\title{
TAIDE JA TODELLISUUDEN TIETÄMISEN KYSYMYS
}

Tero Nauha: Heresy and Provocation. Philofiction. Jälkisanat Peter Pál Belbart. Förlaget, Göteborg 2015.

Performanssitaiteilijan ja taiteentutkijan Tero Nauhan (s. 1970) viime syksynä julkaistu filofiktiivinen teos Heresy and Provocation vie lukijan matkalle Nauhan noin viiden viimeisen vuoden aikana käsittelemiin teemoihin. Kirjan keskiöön nousee erityisesti Nauhan vuonna 2012 Puolan Sleesiassa, Bytomin kaupungin Bobrek-lähiössä tekemä taiteellinen tutkimustyö. Nauha teki Bobrekiin lukuisia vierailuja yhteensä yhdeksän kuukauden aikana. Tutkimusretkillään rappeutuvaan kaivos- ja teollisuuskaupunkiin Nauha kuvasi, haastatteli ja havainnoi Bytomin tunnelmaa. Työskentely tapahtui residenssissä Kronika-taidekeskuksessa, joka on perustettu tukemaan autioituvan kaupungin sosiaalista, taiteellista ja poliittista infrastruktuuria. Bytomissa tehdyn työn tuloksena syntyi Life in Bytom -teossarja, joka sisältää myöhemmin muun muassa Kiasmassa nähdyn performanssin, julistenäyttelyn sekä Wywrotka / Capsizing -elokuvan (2013). Life in Bytomin tuloksia voi lukea myös Nauhan tammikuussa 2016 Taideyliopiston Teatterikorkeakoulussa tarkastetusta väitöskirjasta Schizoproduction: Artistic research and performance in the context of immanent capitalism. Performanssi on nähtävissä videoituna myös teoksen ja tekijän kotisivuilla.

Nauha on siirtynyt taiteellisessa työskentelyssään jatkuvasti teoreettisempaan suuntaan, minkä hänen väitöskirjansakin dokumentoi erinomaisesti. Keskeisiä teoreetikkoja Nauhalle ovat muiden muassa Deleuze ja Guattari,
Lacan ja Laruelle, sekä lukuisat ranskalaiset, italialaiset ja amerikkalaiset ajattelijat. Jos Nauhan varhaisemmissa töissä, kuten kävelyteoksia yhteen kokoavassa Käynti (2009) -teoksessa, tutkimus keskittyy erilaisten ympäristöjen, läsnäolon ja aistihavainnon pohtimiseen, on uudemmissa taideteoksissa ja tutkimuksissa, kuten Life in Bytom tai Man-a-machine: schizoproduction (2014), keskiössä jälkifordistisen kapitalismin runtelema subjekti.

Kyseessä on myös taiteen ja etenkin performanssitaiteen mahdollisuuksien pohtiminen nykyisessä talouden, tiedon ja politiikan "umpikujassa". Teoksessaan Nauha asettaa vastakkain taiteen "lahkolaiset" (secretarians) ja "kerettiläiset". Hänen mukaansa erityisesti performanssitaiteen lahkolaiset protestoivat ja provosoivat, he ovat kommentoimassa sitä mikä näkyy, mikä on esillä ja jatkuvasti läsnä. Kerettiläisillä taas ei ole omaa aluetta, heillä ei ole roolia tällaisessa lahkolaisen taiteen aiheuttamassa spektaakkelia kommentoivassa toiminnassa tai sitä (näennäisesti) järkyttämään pyrkivässä puheessa. Kerettiläisten performanssi tapahtuu hiljaisuuden ja näkymättömyyden sisällä, siellä mitä ei havaita. Kerettiläinen taiteilija tietää, mutta ei filosofisessa mielessä, eikä hän toimi suhteessa näkyvään ja jo-tiedetyn tiedolliseen talouteen. Hänen tiedollaan ei ole perustaa, eikä hänen tietojaan voi käyttää vaihtoarvona. Yksinkertaisesti kerettiläinen ei osallistu näkyvää koskevan tiedon talouteen, eikä kerettiläinen tiedossa eläjä siksi ole Nauhan mukaan myöskään varsinaisesti performanssitaiteilija. Kerettiläinen taiteilija elää ja tietää ikään kuin hän ei enää olisi sisällytetty tähän maailmaan ja sen talouteen. Tässä mielessä kerettiläinen elää lopussa, siinä, 
mikä on päättynyt, siinä mikä ei enää kuulu siihen mikä oli.

Heresy and Provocation ei siksi ole tieteellinen tutkimus tai oikeastaan edes taiteellista tutkimusta. Nimensä mukaisesti kirja on filofiktio. Termin filofiktio Nauha on omaksunut François Laruellelta ja hän määrittelee sen pop-filosofian tai filosofoivan taiteellisen käytännön vastakkaisuutena. Filofiktio pyrkii fiktionalisoimaan filosofian luodakseen asioiden sekoituksen. Sitä luonnehtii epä-filosofinen pyrkimys elää todellisuuden välinpitämättömyyden rinnalla. Filofiktiossa kaikki tiedot, olivat ne sitten filosofista, taiteellista tai fiktionaalista, ovat tasa-arvoisesti päteviä ja tasa-arvoisesti heikkoja todellisen malleja. Ajatuksena on siis eräänlainen filosofiaan ja filosofiseen mielikuvitukseen perustuva fiktio. Siinä ei esitetä tai käsitellä valmiiden ja loppuun saakka puhdistettujen filosofisten väitelauseiden tai teorioiden kenttää, vaan pikemmin seurataan empiirisistä havainnoista ja filosofisesta lukemisesta, muistista ja ajatuksen harhailusta jatkuvasti uudelleen rakentuvaa ja purkautuvaa ajatuksen liikettä, filosofista mielikuvitusta, joka ei koske "asioita sinänsä" vaan niiden erilaisia hahmoja, jälkiä, painaumia ja merkkejä.

Nauhan filofiktio on erityisesti kyseenomaisen subjektin ainutkertaisten mielenliikkeiden ja maisemien auki kirjoittamista. Tämä ei tarkoita, että henkilö tai taiteilija Tero Nauha tilittäisi tai avautuisi teoksessaan. Pikemminkin filofiktio antaa mahdollisuuden seurata yhden mielen kulkemista ja muuntumista. Se ei ole siis humanistiseen ja romanttiseen luovuuteen liitetty "itsen" (self) esitys taideteoksena, vaan pikemmin tallennus siitä mihin kaikkeen materiaaliseen (mielikuviin, tunteisiin, ideoihin, ostoskeskuksiin, luhistuviin kaivoskuiluihin) Nauhan mieli on kytkeytynyt tässä tietyssä ajassa ja paikassa. Sikäli se on ennen kaikkea esi-persoonallista ja persoonien välistä ja myös persooniin välinpitämättömästi suhtautuvaa affektiivista tallentamista.

Tästä syystä Nauhan kirjaa ja sen käyttämää filofiktiivista menetelmää voidaan pitää aidosti materiaalisten affektien auki kirjoittamisena ja avaamisena. Se ei siis ole valmiiksi kulttuurisesti koodattujen tunteiden, kuten rakkauden, vihan tai surun, pohtimista ja projisoimista, vaan esineiden, asioiden, ajatusten ja ihmisten vaikutusten ja kulttuurisesti vielä nimeämättömien ja epämääräisesti liikkuvien a-semioottisten merkkien tallentamista. Kun kapitalismista on tullut immateriaalista, tunteista ja tuntemuksista, asioista jotka olivat ennen unelmaa ja yksityistä, on tullut nyt käsin kosketeltavan materiaalisia ja sosiaalisia. Jos siis jotain, niin Nauhan Heresy and Provocation on eräänlainen ensikäden tallenne jatkuvasti muuttuvista ja liikkuvista affekteista, tallenne siitä mikä ei yleensä tule artikuloiduksi, merkityksellistetyksi tai käsitellyksi.

\section{RUUMIS JA KAPITALISMI}

Koska Nauhan kirja on täysin affektiivinen, käsittelee se myös erityisen paljon ruumista. Oikeastaan kirjan pääteema on ruumiit ja kapitalismi. Rappeutuvan teollisen kaupungin ruumis on täynnä reikiä: kaivoskuiluja jotka puhkovat maan, hylättyjä ja asuinkelvottomia rakennuksia jotka romahtavat kaivoskuiluihin, uusi kauppakeskus joka imee kaikki potentiaalisesti kuluttavat subjektit sisäänsä muutamasta aukosta ja ulostaa heidät tyhjinä samoista aukoistaan. Narkomaaneja joiden kädet ovat täynnä reikiä. Narkomaaneja, prostituoituja ja juoppoja joiden silmät ovat enää vain aukkoja kuolemaan ja tyhjyyteen johon koko Bobrek on vajoamassa. Nämä aukot eivät ole enää liittymisen ja vaihdannan aukkoja tai kytkeytymisalustoja, sillä niissä virtaa ainoastaan se millä ei ole merkitystä tai jota ei voi merkitä. Nämä ovat kytketyn sarjan viimeisiä aukkoja, jonka jälkeen ei ole mitään.

Kirjan kansikuva on täynnä luurankoja, jotka ovat yhtäältä elävän lihan ja affektien rakenteita, toisaalta jäänteitä ja muistoja niistä suurista kapitalistisista koneista ja talousjärjestelmistä, jotka joskus pitivät Sleesiaa yllä ja 
joiden varassa se kukoisti yli sata vuotta yhtenä Keski-Euroopan vauraimmista kaivosalueista. Nyt Bytomissa vaeltaa hylättyjen työläissubjektien ruumiita tietämättä mihin mennä, ruumiita jotka kituvat kylmän talven ja hengityksen salpaavan ruskohiilen katkussa. Ruumiita hiiltä tuottaneessa kaupungissa, jossa sitä nyt täytyy varastaa pysyäkseen lämpimänä. Ovatko nämä ruumiit hirviöitä? Mikä on se ruumis, joka hajoaa uuden liikekeskuksen pyöröoviin avajaispäivänä? Mikä on se ruumis, joka on kasattu monista osista, palasista? Liitoksistaan hajoava työväenluokka, jolla ei ole enää voimaa ja joka ei pelota enää ketään. Ruumis ja maa sieninä, jotka imevät kaiken mitä niihin kaadetaan ja jotka säilyttävät sen kunnes se puristetaan niistä ulos. Sieni on epätaloudellinen ruumis, sillä se säilöö eikä muunna tai lisää virtausta.

Näiden solidaarisuuden ja yhteisöllisyyden aaveruumiiden keskellä on taiteilijan ruumis joka kulkee, katsoo, tunkeutuu ja kaivaa päättymättömästi kuten entiset kaivostyöläiset satoja metrejä kaupungin alla. Yhteisöllisyyden ja solidaarisuuden ruumis, työväenluokan yhteensidottu tai -kytketty voimakas ja sankarillinen ruumis on muuttunut lukuisten uusliberaalien yksilöllisten onkaloiden ja subjektiivisten kaivoskäytävien sieneksi. Tämä sieni pidättelee kuravettään Euroopan keskiössä sijaitsevassa peräaukossa. Tämä peräaukko ei kiinnity mihinkään. Tähän teollisen kapitalismin virta katkeaa, eikä se muutu jälkiteolliseksi trendikkääksi hipster-virraksi, vallatuiksi ja vähitellen gentrifioiduiksi kortteleiksi, kaupunginosiksi tai kaupungeiksi, vaan kuonaksi ja jätteeksi joka on silmiemme edessä, mutta jolle ei voi tehdä mitään. Teollisuuden käyttökelvoton uloste ja jäte. Mätänevä ruumis johon ei voi ja johon kukaan ei halua koskea.

Siihen tarttuu vain taiteilija, joka kerää materiaalia, kuten Tarkovskin filmatisoima Stalker alueelta. Siinä missä Stalker etsii Jumalaa, etsii taiteilija todellista. Taiteilijan ruumiin on muututtava jatkuvasti: sen on tultava kaivostyöläiseksi, sotkettava kasvonsa nokeen, kuunneltava aikakauden iskelmää ja sen jälkeen romahdettava teollisuuden loppuessa. Taiteilija suunnistaa sienikaupungin taitteissa, seuraa loputtomia työläissubjektien kaivamia käytäviä eikä näe ympärilleen valkoisesta kankaasta tehdystä onkalostaan. Elämme kapitalismin taitteessa (le pli), jossa toiset ovat aivan vieressä, naapurihuoneistoissa, viereisellä käytävällä tai kadulla, mutta emme näe heitä emmekä kytkeydy heihin. Tässä tunnistaa Leibnizin barokin affektiivisen muunnelman, jossa ainoa valo on taiteilijan mukana kulkeva aistihavainto ja sen installaatio. Tämä on huonoin mahdollisista maailmoista, mutta silti monille ainoa.

\section{TAITEILIJAN POLITIIKKA}

Mutta mikä taiteilija on? Kirjan alussa taiteilija on lihaa, koira, puhdasta halua, prostituoitu, despootti ja palvelija. Koska taiteilija on lihaa ja materiaa, hän vaikuttaa olevan jotain filosofialle ja järjelle, jopa tietämiselle vastakkaista. Taiteilijan järki ei ole "riittävää". Taiteilija on levoton, eläin, jotain mikä pitää itseään elämää suurempana. Hän pitää itseään kerettiläisenä, joka ei ole kytkeytynyt mihinkään. Pitää itseään jonakin. Hän pitää itseään muuna kuin Bobrekin asukkaat, vaikka pyrkii tulemaan sellaiseksi. Taiteilija on ulkopuolinen joka kulkee Bobrekin ihmisten keskellä, ostoskeskuksissa, hylätyissä kaivoksissa ja jätekasoilla. Taiteilijalta odotetaan, että hän pyrkii provosoimaan. Ärsyttämään ja sanomaan ääneen sen mikä on ilmeistä ja mikä meitä kaikkia häiritsee.

Nauhan taiteilija on kuitenkin kerettiläinen, ulkopuolinen ilman omaa maata tai ääntä, ilman tarvetta ilmaista "omaa itseään”. Siksi taiteilija on mahdollisesti myös poliittinen: se joka paljastaa Bobrekin tuntemattoman maiseman, joka kulkee tunneleiden läpi ja lävistää taitteiden kaikki poimut ja saavuttaa näin tietoa, elää tiedossa. Siksi taiteilija on myös filosofi. Sillä mitä muuta filosofia perustaltaan on kuin mielen liikettä, mielten liikkeiden seuraa- 
mista, niiden jäljittelyä, järjestämistä ja niihin tarttumista. Filosofit ovat korostaneet perinteisesti aivan liian vähän sitä, kuinka mieli liikkuu juuri siksi, että ruumis liikkuu. Toisin sanoen sitä, että mieli on materiaa. Filosofia ja taide alkavat silloin kun ruumis kokee jotain mitä se ei voi ymmärtää (affektoituu), jotain mitä se ei voi sanallistaa, merkitä ja merkityksellistää. Silloin mieli hämmästyy ja joutuu pohtimaan rumistaan ja ruumiillisuuttaan, havaintoaan maailmasta, joka on kaikkien affektiivisten kokemusten lailla enemmän kuin Järki voi sillä hetkellä ymmärtää. Tällaisessa tilassa, tai epätilassa, Järki ei riitä, vaan se hämmentyy ja hämmästyy, sekoaa ja alkaa etsiä pakoreittiä johonkin merkitykseen, tarkoitukseen ja selitykseen. Siksi ruumis tuo mielen takaisin todelliseen, sillä todellinen vastustaa riittävää Järkeä, riittäviä selityksiä, riittäviä ja yksinkertaisiksi muodostuneita merkkejä.

Juuri tätä tapahtuu Nauhan Heresy and Provocation -teoksessa. Ruumis on kerettiläinen, vääräoppinen. Se esittää jotain mikä on eksessiivistä, liiallista suhteessa siihen mitä Järki jo tietää ja jonka se voi juuri nyt jo ymmärtää. Kerettiläinen taiteilija tai Bobrekin ruumis esittää tulevaisuuden avautuman joka on väistämättä poliittinen, koska se vaatii jonkin muun tai uuden tietämistä ja käsittelemistä. Tämä toiminta ei ole ilmeisen provosoimista, vaan ilmeettömäksi muuttuneen liikuttamista ja olevaksi tekemistä.

Siksi Nauhan taitelija, kerettiläinen ja havainnoiden, jätteistä ja hajoavista ruumiista todistaen etenevä kulkija on myös poliitikko. Poliitikkona taiteilija tuo näkyviin julkiselle alueelle sen mitä emme näe. Hän tuo näkyviin Sleesian teollisuusihmeen rappion, prostituution, narkomaanit, juopot, kerjäläiset, köyhät ja nälkäiset; entiset työläisruumiit jotka rakensivat maailman ja porasivat maan täyteen reikiä, jotka nyt hukutetaan noihin hautakammioihin. Taiteilija todistaa murjotusta ruumista, joka pakottaa ajattelemaan, nimeämään, käsittelemään ja käsitteellistämään teollisuuden jälkiä ja muistoja, kaivosteollisuuden repimiä reikiä ja sen tuottamia jätteitä. Kerettiläinen taiteilija ei pyri järkyttämään Bobrekin ihmisiä tai näyttämään heille peilissä heidän jokapäiväisen elämänsä irvokkuutta, kuten lahkolainen taide usein tekee. Lahkolaistaiteen tehtävänä on kyynisen ja nihilistisen asenteen tuottaminen ihmisen omaan elämään, mutta kerettiläisen sydän on aivan liian lämmin tällaiselle kylmyydelle ja tuotteistamiselle.

Siksi kerettiläisen taiteilijan politiikassa epämääräisyys ja epäjärjestys tulevat näkyviksi järjestyksen sijaan, erimielisyys ja erityisesti ruumiiden affektit nousevat esiin Järjen sijaan yhtä vaativina kuin huonosti haudatut luut ja luurangot. Taiteilijan politiikka tuo näkyväksi jotain mikä ei ole olemassa, mitä ei voi havaita: maahan kätketyt onkalot, ihmisten mieliin kätketyt luolat, muistot, kaupunkiin kätketyt tarinat ja elämät. Kaikki tämä ottaa hirviömäisen muodon, erilaiset jäsenet yhdistyvät, mutta elämä esittäytyy silti ilman organisaatiota tai järjestystä.

Kapitalistisessa maailmassa on kerettiläistä elää tai kuvitella elävänsä ilman kapitalismia ja sen talouksia. On harhaoppista ja "naiivia" esittää, että elämä on mahdollista ilman kapitalismia ja sen tuottamaa ymmärrystä ja järkeä. Kuinka elämä voisi toimia tai toteutua ilman kapitalismia? Bytomissa ongelmat alkoivat siinä vaiheessa kun kapitalismi vetäytyi, kun louhokset köyhtyivät eikä kaivannaisille ollut kysyntää. Mitä jää jäljelle, muuta kuin kapitalismin jäljet ja jätteet? Onko Bytomissa elämää ilman kapitalismia, onko tämä mahdollista muualla? Kuinka ruumis, kaupunki ja työläisruumis, joka on romahtanut kapitalismin rakenteiden poistuttua, voi enää toipua tai jatkua? Onko ruumiilla elämää ilman kapitalismin voimaa, ja millaista tuo elämä on? Mistä se voi saada rakenteen, ettei se ole vain sieni ja aave? Kuinka uudet kytkökset syntyvät?

Nauhan teokset, niin Heresy and Provocation kuin Life in Bytom osoittavat, että kapitalismin järjestys ei tuhoa ruumista, vaikka tekeekin siitä kapitalismin estetiikkaan ja järjestykseen tottuneille subjekteille ainakin het- 
kellisesti epähaluttavan ja ruman. Mutta juuri siksi, juuri rumuudessaan ruumis on ainoa mikä vastustaa ja hylkii kapitalismia. "Kaikki on totta, kaikki ajattelee, ei-mikään on.” Nauhan Heresy and Provocation on haastava teos ja tutkielma kapitalismin lopusta, ruumiista, politiikasta ja filosofiasta. Se epäilemättä haastaa

\section{KIRJALLISUUS}

Gilles Deleuze (1988): Le Pli. Leibniz et le baroque. Les éditions de minuit. Paris

Kronika: Kronikan kotisivut: URL: http://www.kronika. org.pl/en/about

François Laruelle (2010): Future Christ. A Lesson in Heresy. Käänt. Anthony Paul Smith. London: Continuum.

Tero Nauha (2009): Käynti. Siuron paino.

Tero Nauha: Life in Bytom -kotisivut. URL: http://lifein- myös taidekenttää pohtimaan ja käsittelemään sitä, mikä on totta ja todellista, mutta jolle ei vielä ole ilmaisua, ääntä, muotoa tai kieltä. Toisin sanoen se herättää jälleen pohtimaan taiteen poliittisuuden mahdollisuutta ilmeisen kyynisen provokaation sijaan.

- MIKKO JAKONEN

$$
\text { bytom.org/ }
$$

Tero Nauha: Life in Bytom performanssi ja näyttely Kronika-taidekeskuksessa tammikuussa 2016.

Tero Nauha (2015): Heresy and Provocation. Philofiction. Jälkisanat Peter Pál Belbart. Förlaget, Göteborg.

Tero Nauha: Tero Nauban Kotisivut.URL: http://teronauha.com/

Andrei Tarkovski (1979): Stalker. Mosfilm. 